Gut, 1983, 24, 218-221

\title{
Electrical activity of the external anal sphincter at different ages in childhood
}

\author{
MARIE-LOUISE MOLANDER AND B FRENCKNER \\ From the Departme'nt of Paediatric Surgery, St Göran's Hospital, Stockholm. Sweden
}

SUMmaRY In EMG recordings of the external anal sphincter there is a brief contraction in response to rapid rectal distension, and a preserved or increased activity during a prolonged substantial rectal distension in healthy adults. In order to determine if this activity develops during childhood 30 healthy children, aged 2 months to 15 years, were examined with their parents' consent. EMG of the external anal sphincter during rest and during rectal distension was performed. All those children who had gained voluntary anal control showed an EMG recording similar to the adults. The 10 youngest children who had not gained voluntary control showed another EMG pattern. Instead of a brief contraction they had a brief loss of activity in response to rectal distension. During a prolonged rectal distension the external sphincter activity decreased and finally ceased. An intermediate state was found in the two youngest children who had gained voluntary control. The EMG pattern showed a good correlation with the maturation and gain of voluntary control of defaecation.

The activity of the external anal sphincter is influenced not only by voluntary effort but also by spinal and supraspinal reflexes, which are considered to be of great importance for anal continence. In spite of being a striated muscle the external anal sphincter has a tonic, continuous activity at rest, ${ }^{12}$ which is maintained by a spinal reflex arc. ${ }^{3-5} \mathrm{~A}$ spinal centre also mediates what has been termed the inflation reflex - a brief contraction in response to rectal distension. ${ }^{6}{ }^{7}$ In healthy adults this inflation reflex may be intensified by a supraspinal influence, which also induces continuous or raised activity of the external sphincter during prolonged rectal fullness. ${ }^{8}$

Relatively little is known about the external anal sphincter's behaviour in infancy. The aim of the present investigation was to evaluate the development of this sphincter's activity from infancy through childhood by means of EMG recordings at rest and during rectal fullness.

\section{Methods}

\section{SUBJECTS}

With the parents' consent the study was undertaken on 30 children admitted to hospital for minor

Received for publication 8 June 1982 operations such as herniotomy or circumcision. None of the children had any history of gastrointestinal or anal disorders. They were divided into three groups. Group I comprised 10 children aged 2 months to $1 \frac{1}{2}$ years, group II 10 children aged $2 \frac{1}{2}$ to 8 years, and group III 10 children aged $9 \frac{1}{2}$ to 15 years.

None of the children in group I had voluntary control of defaecation, while such control had been attained by all the children in groups II and III. The two youngest children in group II, $2 \frac{1}{2}$ and 4 years of age, had gained control recently.

The study was approved by the ethical committee at Karolinska Institutet, Stockholm. All parents were informed and gave their consent.

\section{EQUIPMENT}

EMG activity from the external anal sphincter was recorded by means of two surface electrodes placed just outside the anal orifice. Prefabricated ordinary ECG electrodes were used (Pregelled Disposable NeoNatal electrodes for ECG and Apnea Monitoring, Andover Medical Incorp. USA). In order to fit the anal orifice, the rounded pregelled plastic plate was reduced by cutting it diagonally, leaving the electrode knob at the cut margin. The patient was earthed with a similar electrode. Rectal distension was achieved with a latex balloon. When empty, this measured $1 \cdot 5-2 \mathrm{~cm}$. It was connected to 
a polyethylene tube about $50 \mathrm{~cm}$ long, leading to the recording equipment via a three-way stopcock, through which air could be inflated into the balloon. The rectal balloon pressure and EMG were recorded on a Grass 7 recorder. The rectal balloon was connected to the recorder via a pressure transducer (Statham P23) and amplifier (Grass 7 P1) and the EMG electrodes via an EMG amplifier (Grass 7 P3).

The examination was performed by one author. The records were interpreted independently by the authors and the non-investigating author had no knowledge of the patients' ages.

\section{PROCEDURE}

Children below 2 years of age (group I) were examined lying on their backs with hips and knees in flexion. Older children (groups II and III) lay on their left side, also with hips and knees in flexion. The rectal balloon was inserted into the rectal ampulla and the electrodes were placed opposite each other at the anal verge. An assistant kept the balloon in position and prevented the electrodes from touching each other. The EMG activity was recorded continuously. When the child was calm, the balloon was successively filled with air, in portions of 5 and $10 \mathrm{ml}$ in group I and $20 \mathrm{ml}$ in groups II and III. Each inflation was done rapidly, in approximately $(0.5$ seconds after an interval of 20-30 seconds. The successive distension was stopped when the child showed any sign of discomfort. The children were examined without medical sedation. They were mostly kept calm by the parents, aided in some cases by a feeding bottle.

\section{Results}

\section{CHILIDEN WITH VOLUNTARY DEFAECATION} CONTROL, GROUPS II AND III

At rest, activity of the external anal sphincter was registered in all these children (Fig. 1). The activity was continuous and varied very little in the course of an examination in each child.

In response to a rectal distension an inflation reflex was recorded in all children but the second youngest (Table, Fig. 1). This child, aged 4 years, showed unaltered activity. The contraction of the external anal sphincter - that is, the inflation reflex lasted for 0.7 to 2 seconds (mean one second).

The inflation reflex recurred at most of the
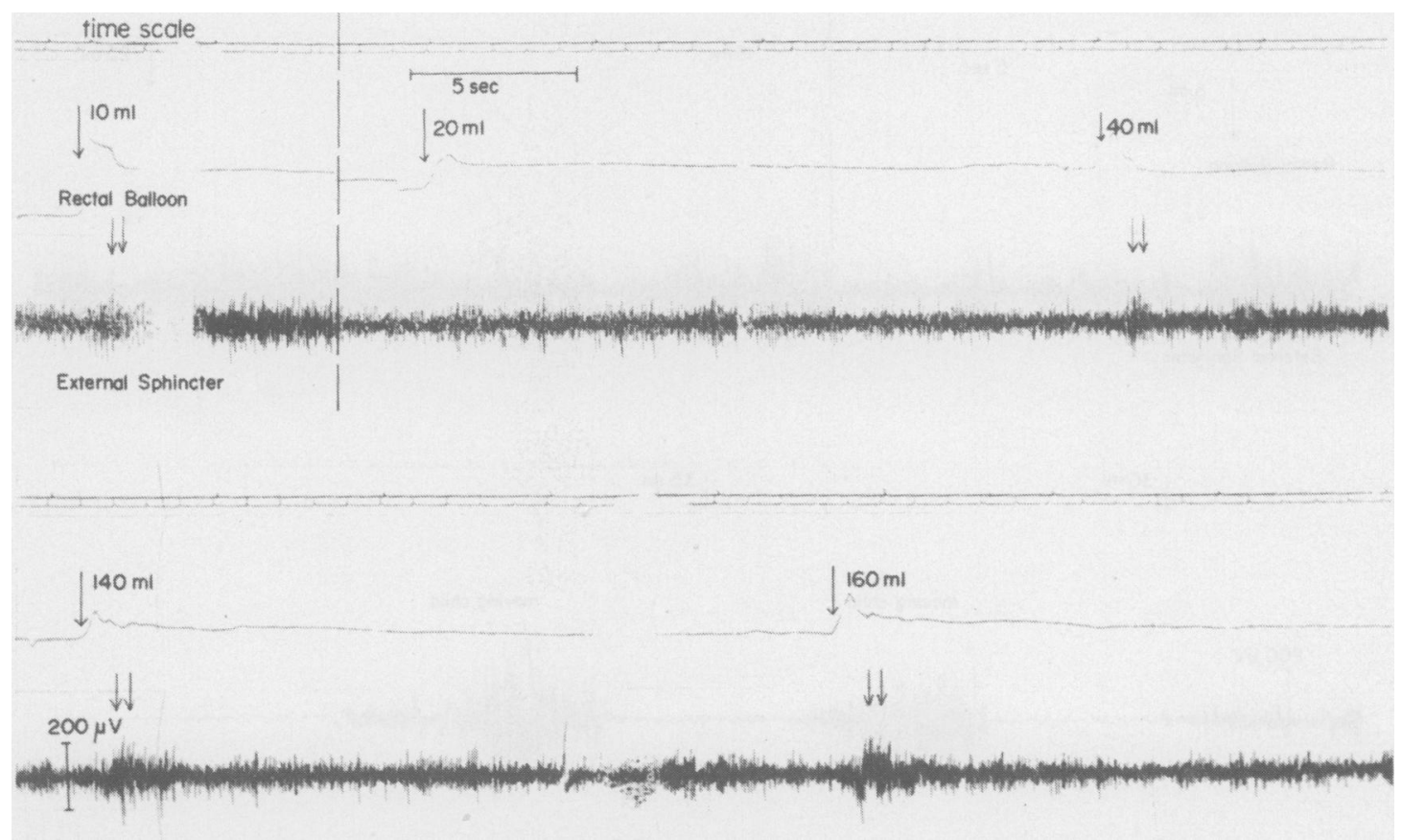

Fig. 1 EMG recording of external anal sphincter during rectal distension in 12 year old boy. In response to each rectal inflation there is an inflation reflex. Between different inflations there is well-preserved activity. Rectal inflations are indicated by single arrows. Double arrows indicate inflation reflexes. 
Table EM(; activity of the external anal sphincter in groups I-III. The figures indicate the number of children in whom the different reflexes and activities were recorded

\begin{tabular}{|c|c|c|c|c|c|}
\hline Group & Age & $\begin{array}{l}\text { Con- } \\
\text { timuous } \\
\text { activity } \\
\text { at rest }\end{array}$ & $\begin{array}{l}\text { Infla- } \\
\text { tion } \\
\text { reflex }\end{array}$ & $\begin{array}{l}\text { Inhibi- } \\
\text { tion } \\
\text { reflex }\end{array}$ & $\begin{array}{l}\text { Preserved } \\
\text { activity }\end{array}$ \\
\hline I & $2-18$ months & 10 & - & 10 & - \\
\hline II & $21-8$ years & 10 & 9 & - & 9 \\
\hline III & $9 \frac{1}{2}-15$ ycars & 10 & 10 & - & 10 \\
\hline
\end{tabular}

successive inflations (Fig. 1). Between inflations the activity was the same as or above the resting activity in all children but one (Table). This child, the youngest in this group ( $2 \frac{1}{2}$ years of age), showed instead a successively lowered activity until the balloon was expelled at a rectal volume of $70 \mathrm{ml}$. Mean expansion of the rectal balloon was $120 \mathrm{ml}$ (range $60-200 \mathrm{ml}, \mathrm{SD} 48 \mathrm{ml}$ ) in group II and with $200 \mathrm{ml}$ (range 140-260 ml. SD $42 \mathrm{ml}$ ) in group III.

\section{CHILDREN WITHOUT VOLUNTARY DEFAECATION} CONTROL, GROUP I

At rest, these children likewise showed continuous activity of the external anal sphincter.

In response to the rectal distensions, none of these children showed an inflation reflex. On the contrary, lowered or totally absent activity was recorded for a short time, duration (0.3 to 2 seconds (mean 0.8 second) (Table, Fig. 2).

The lowered activity recurred at most of the successive inflations in all patients. Between inflations these children showed a successive lowering of the continuous activity of the external anal sphincter, until this ceased completely (Table, Fig. 2). Only the oldest child had some activity left when signs of discomfort appeared at a rectal fullness of $80 \mathrm{ml}$. All but the oldest three of the children who successively lowered their activity, also defaecated the rectal balloon (mean rectal volume $20 \mathrm{ml}$, SD $7 \mathrm{ml}$, range $10-30 \mathrm{ml}$ ).

\section{Discussion}

Although the pelvic floor consists of striated muscle, it displays tonic, continuous activity at rest. This activity originates from a spinal centre, as it persists after transection of the spinal cord. ${ }^{4}$ The present investigation shows that tonic continuous activity of

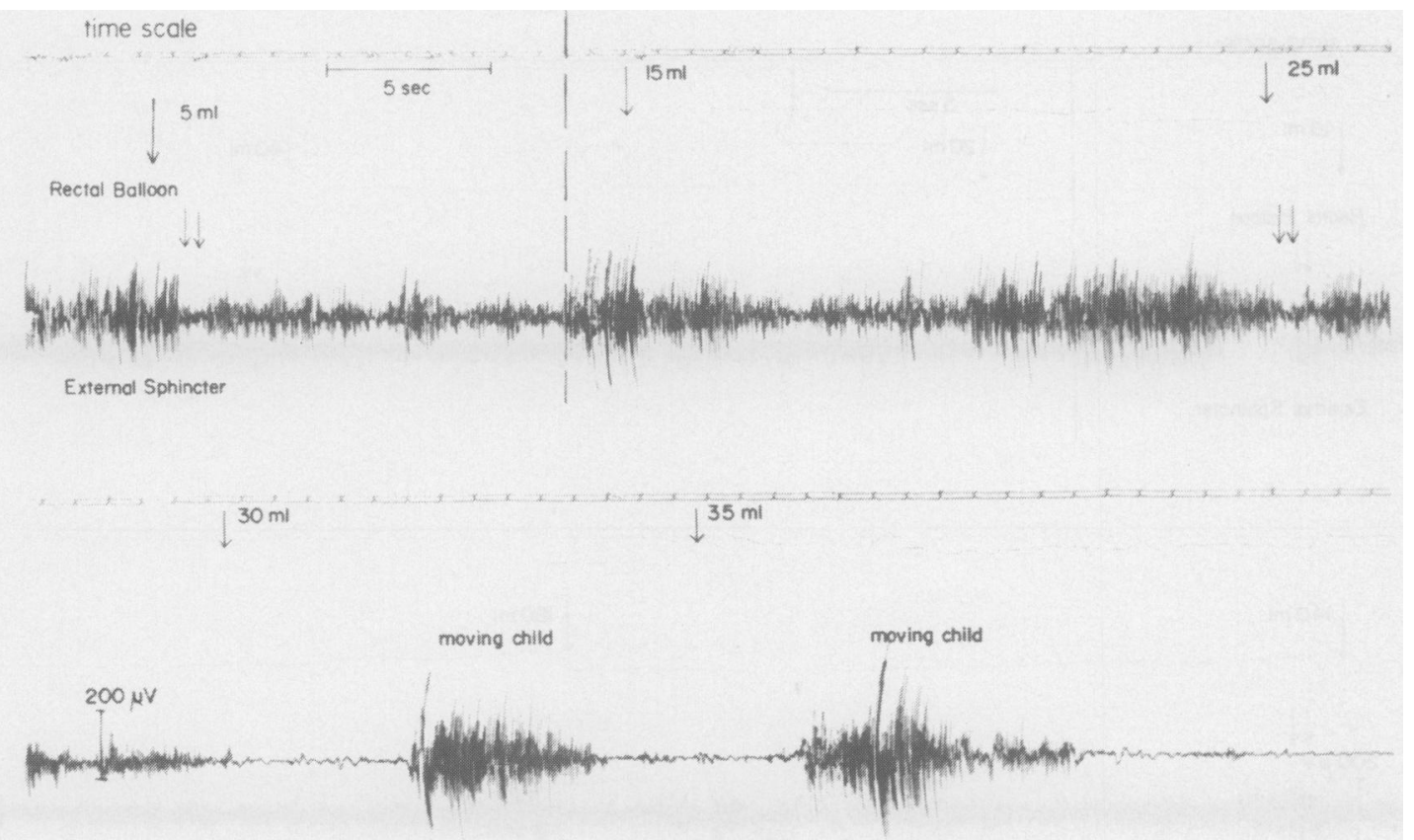

Fig. 2 EMG recording of external anal sphincter during rectal distension in 3 month old boy. In response to most rectal inflations there is inhibition reflex. Between different inflations activity is successfully lowered. On two occasions child was moving, giving misguiding activities. Rectal inflations are indicted by single arrows. Double arrows indicate inhibition reflexes. 
the external sphincter is present in infancy. This agrees with the impression gained at a physical examination with anal manipulations of these children.

Normally, rectal distension elicits a brief contraction of the striated anal sphincter muscles. This response, first reported by Gaston, ${ }^{h}$ has been called the inflation reflex. The reflex is present in spinal man but at larger rectal volumes than in healthy persons, which implies that it too is facilitated by supraspinal activity. ${ }^{8}$ In the present investigation no inflation reflex was recorded in the youngest children, who had not yet gained voluntary defaecation control. On the contrary, they showed decreased or even absent activity of the external sphincter for about half a second. We have called this inhibition reflex. We do not think that this is an artefact. The inhibition reflex was observed in all children in group I and it recurred in response to most of the successive inflations. The older children exhibited normal inflation reflexes, in accordance with findings in adults. We have interpreted the inhibition reflex as a sign of immaturity, and this change from inhibition reflex to inflation reflex as a part of the normal maturation process correlated to development of the voluntary control of the defaecation.

As rectal distension was successively increased, most of the inflation reflexes as well as the inhibition reflexes recurred. Between the rectal inflations, all children who had gained voluntary defaecation control - apart from the youngest one - showed well-preserved activity of the external sphincter, in accordance with the picture in adults. ${ }^{6}$ This is because of a supraspinal influence, as external sphincter activity ceases entirely during gradual rectal distension in spinal man. ${ }^{8}$

The youngest children, who lacked voluntary defaecation control, slowly lost their activity as rectal distension was increased. The activity ceased before the children gave any sign of discomfort indicating that the rectal ampulla was not physiologically over-distended. Consequently, it seems that the supraspinal activity, which confers preserved sphincter activity, is not yet developed in these children. For these, the youngest children, the inhibition reflex and the lack of activity during prolonged rectal distension are probably part of their normal defaecation pattern. This may help to explain the fact that they defaecated the balloon during the examination. It also correlates to the well known fact that rectal manipulation elicits a defaecation in infants. As soon as the children had gained anal control, they showed mature reflexes of the external anal sphincter - that is, an inflation reflex and preserved activity during prolonged rectal distension. We believed these activities to be of great importance for the development of voluntary anal control.

\section{References}

1 Floyd WF, Walls EW. Electromyography of the sphincter ani externus in man. J Physiol 1953; 122: 599-609.

2 Kawakami M. Electro-myographic investigation on the human external sphincter muscles of anus. Jpn $J$ Physiol 1954; 4: 196-204.

3 Porter NH. A physiological study of the pelvic floor in rectal prolapse. Ann Roy Coll Surg 1962; 31: 379-404.

4 Parks AG, Porter NH, Melzak J. Experimental study of the reflex mechanism controlling the muscles of the pelvic floor. Dis Colon Rectum 1962; 5: 407-14.

5 Melzak J, Porter NH. Studies of the reflex activity of the external sphincter ani in spinal man. Paraplegia 1964; 1-2: 277-96.

6 Ihre T. Studies on anal function in continent and incontinent patients. Scand J Gastroenterol 1974; suppl 25.

7 Gaston EA. The physiology of fecal continence. Surg Gynec Obstet 1948; 87: 280-90.

8 Frenckner B. Function of the anal sphincters in spinal man. Gut 1975; 16: 638-44. 